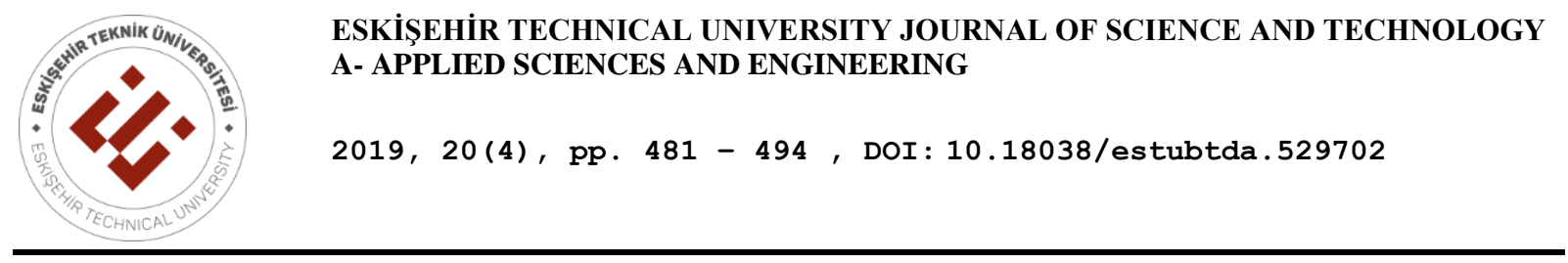

\title{
GREEN SYNTHESIS OF SILVER NANOPARTICLES AS AN ANTIBACTERIAL AGENT: OPTIMIZATION OF SYNTHESIS CONDITIONS WITH RESPONSE SURFACE METHODOLOGY
}

\author{
Semra ARSLANTÜRK ${ }^{1}$, Deniz UZUNOĞLU ${ }^{*}$, Esma ESER ${ }^{2}$, H. İbrahim EKİZ², Ayla ÖZER ${ }^{1}$ \\ ${ }^{1}$ Department of Chemical Engineering, Engineering Faculty, Mersin University, Mersin, Turkey. \\ ${ }^{2}$ Department of Food Engineering, Mersin University, Engineering Faculty, Mersin, Turkey.
}

\begin{abstract}
In the present work, the synthesis of silver nanoparticles (AgNPs) through a green synthesis method using avocado (Persea americana) leaf as a biological reductant and capping agent. The synthesized AgNPs were characterized by zetasizer, FTIR, UV-vis spectrophotometer, XRD, and SEM. Besides, response surface methodology was used to understand and optimize the effect of the experimental parameters on the green synthesis of AgNPs. Three experimental parameters were chosen as independent variables: temperature, $\mathrm{AgNO}_{3}$ concentration, and aqueous leaf extract volume. A quadratic model was established as a functional relationship between three independent variables and the effective hydrodynamic diameter (nm) of AgNPs. The results of model fitting and statistical analysis demonstrated that only $\mathrm{AgNO}_{3}$ concentration was statistically significant parameter. The optimum conditions for minimum effective hydrodynamic diameter ( $\mathrm{nm}$ ) of AgNPs $(32.74 \mathrm{~nm})$ were temperature of $25^{\circ} \mathrm{C}, \mathrm{AgNO}_{3}$ concentration of $0.001 \mathrm{M}$, and aqueous leaf extract volume of $50 \mathrm{~mL}$. Moreover, the antibacterial activities of AgNPs for S. typhimurium, E. coli O157:H7, S. aureus, and L. monocytogenes were tested and it was found that AgNPs had stronger inhibitory effects on growth of L. monocytogenes than the other bacteria.
\end{abstract}

Keywords: Antibacterial activity, Avocado leaf, Optimization, Response surface methodology, Silver nanoparticles

\section{INTRODUCTION}

Silver nanoparticles (AgNPs) are amongst the crucial metallic nanomaterials that have become the focus of much investigation interest due to their unique optical, electrical, and biological properties which makes them to be used in various application areas such as catalysis, water treatment, electronics, biomedical, agriculture, food industry (packaging), accessories, animal husbandry, cosmetics, military, and textile industry. Besides, AgNPs are of significant interest in the area of especially biological systems, living organisms, and medicine because they are regarded safe and nontoxic inorganic antibacterial agents, which have been described as "oligodynamic" due to its ability to exhibit bactericidal effect at even low concentrations [1]. There are various synthesis methods of metallic nanomaterials that include physical, chemical, and biological routes like sonochemical reduction, microwave assisted process, hydrothermal synthesis, electro-chemical method, reverse micelles/microemulsion method, green synthesis, and chemical reduction [2]. Among these methods, physical and chemical processes generally require to use of expensive and hazardous chemicals as well as high energy (high pressure and/or temperature). However, in the green synthesis method, environmental-friendly and biocompatible reagents are used in order to minimize the toxicity of the resulting nanomaterials and the environmental impact of the byproducts [3]. The basis of the green synthesis method is the reduction from the metal salt with the aid of the biological agents such as plant, algae, bacteria, and fungi. It is generally preferred to use plants, renewable sources, as reducing and capping agents for the nanoparticle synthesis because the green synthesis method using plants eliminates process of cell culturing and also it is a simple, efficient and low cost route [1]. Besides, the investigation of the effects of experimental conditions on the nanoparticle synthesis have become very important

*Corresponding Author: denizuzunoglu4@gmail.com

Received: 20.02.2019 Published: 30.12.2019 
research area in order to understand and interpret the synthesis mechanisms. For this purpose, the optimization analysis could be evaluated by the traditional and statistical techniques. The optimization by the traditional 'one-factor-at-a-time' technique, where a single factor is varied while others are kept constant, requires a considerable amount of work and time; hence, alternative statistical optimization techniques like response surface methodology (RSM) have been developed. The conventional optimization technique do not take into account the possible interaction of various independent factors while RSM can be used to evaluate the relationship between a set of controllable experimental factors and observed results with limited number of experiments [4].

The aim of the present work is to synthesize of AgNPs by a fast, simple (one-step), environmentalfriendly, and low-cost route using avocado (Persea americana) leaf, which acts as both reducing and stabilizing agent. Besides, the effects of experimental conditions on the green synthesis of AgNPs were investigated with response surface methodology (RSM), the most widely used statistical technique for process optimization. Moreover, the antibacterial activity of AgNPs was tested against common foodborne pathogens such as S. typhimurium, E. coli $\mathrm{O} 157: \mathrm{H} 7$, S. aureus, and L. monocytogenes.

\section{MATERIALS AND METHODS}

\subsection{Green Synthesis and Characterization of AgNPs}

\subsubsection{Extraction from avocado (Persea americana) leaves}

The aqueous leaf extract, as a biological reducing and capping agent, was prepared for the green synthesis of AgNPs. For this purpose; $10 \mathrm{~g}$ of the purified and dried avocado (Persea americana) leaves were boiled in $500 \mathrm{~mL}$ of distilled water at $100{ }^{\circ} \mathrm{C}$ for $5.0 \mathrm{~h}$. After cooling at room temperature, the brown aqueous leaf extract was filtered using by Whatman no. 1 filter paper and then, it was stored in a refrigerator at $+4{ }^{\circ} \mathrm{C}$.

\subsubsection{Synthesis and Characterization of AgNPs}

The required volume of the aqueous leaf extract was added to $100 \mathrm{~mL}$ of $\mathrm{AgNO}_{3}$ at the required concentration in the conical flasks. Then, they were shaken in an agitation vessel at constant temperature for $1.0 \mathrm{~h}$. They were allowed to stand at the reaction temperature for 1.0 day to be accomplished the synthesis. After that, the resulting mixture was centrifuged at $4000 \mathrm{rev} / \mathrm{min}$ for $10 \mathrm{~min}$ and the precipitated AgNPs were washed with distilled water. They were dried at $110{ }^{\circ} \mathrm{C}$ in an oven for $24 \mathrm{~h}$, and were stored at $+4{ }^{\circ} \mathrm{C}$ in the refrigerator [5]. The characterization studies of AgNPs were performed by zetasizer (Malvern, UK) using Dynamic Light Scattering (DLS) technique, Fourier Transform Infrared Spectrometer (FTIR- Perkin Elmer, Shelton), X-ray Diffractometer (XRD- Philips XPert, Netherlands), and Scanning Electron Microscope (SEM- Zeiss/Supra 55, Germany).

\subsection{Experimental Design and Optimization using Response Surface Methodology}

The face centered central composite design (CCD) with free Minitab 17 software (Minitab Inc.) for the response surface methodology (RSM) was employed to optimize the experimental conditions such as temperature, $\mathrm{AgNO}_{3}$ concentration, and aqueous leaf extract volume for green synthesis of AgNPs. The ranges and levels of the independent variables for the experimental design strategy were shown in Table 1 whilst the experimental design along with the responses for the effect of three independent variables in 20 sets of experiments was presented in Table 2. 
Table 1. The ranges and levels of the independent variables

\begin{tabular}{ccccc}
\hline \multirow{2}{*}{ Symbol } & \multirow{2}{*}{ Independent variable } & Cow $(-\mathbf{1})$ & Ceded levels \\
\cline { 3 - 4 } & & 25 & 45 & High (+1) \\
\hline $\mathrm{A}$ & Temperature $\left({ }^{\circ} \mathrm{C}\right)$ & 0.0010 & 0.0505 & 65 \\
$\mathrm{~B}$ & $\mathrm{AgNO}_{3}$ concentration $(\mathrm{M})$ & 10 & 30 & 0.1000 \\
$\mathrm{C}$ & Aqueous leaf extract volume $(\mathrm{mL})$ & 50 \\
\hline
\end{tabular}

The responses are correlated to the factors by linear or quadratic models in order to observe the optimum conditions A quadratic model involved the linear model is presented as [6];

$$
\mathrm{Y}=\mathrm{b}_{0}+\mathrm{b}_{1} \mathrm{~A}+\mathrm{b}_{2} \mathrm{~B}+\mathrm{b}_{3} \mathrm{C}+\mathrm{b}_{11} \mathrm{~A}^{2}+\mathrm{b}_{22} \mathrm{~B}^{2}+\mathrm{b}_{33} \mathrm{C}^{2}+\mathrm{b}_{12} \mathrm{AB}+\mathrm{b}_{13} \mathrm{AC}+\mathrm{b}_{23} \mathrm{BC}
$$

where $\mathrm{Y}$ shows the response of the effective hydrodynamic diameter $(\mathrm{nm})$ of AgNPs, where $\mathrm{b}_{0}$ is intercept term, $b_{1}, b_{2}$, and $b_{3}$ are linear coefficients, $b_{11}, b_{22}$, and $b_{33}$ are quadratic coefficients, $b_{12}, b_{13}$, and $\mathrm{b}_{23}$ are interactive coefficients, and the independent variables are coded $\mathrm{A}, \mathrm{B}$, and $\mathrm{C}$. The interaction between the independent variables and the responses was tested by using ANOVA and the effect of the variables was also evaluated with response surface graphs.

Table 2. The experimental design with the obtained responses

\begin{tabular}{ccccc}
\hline \multirow{2}{*}{ Run order } & \multicolumn{3}{c}{ Independent variables } & Response \\
\cline { 2 - 5 } & $\mathbf{A}$ & $\mathbf{B}$ & $\mathbf{C}$ & Y \\
\hline 1 & 25 & 0.1000 & 10 & 127.56 \\
2 & 65 & 0.0010 & 50 & 44.00 \\
3 & 45 & 0.0010 & 30 & 66.00 \\
4 & 65 & 0.0505 & 30 & 43.41 \\
5 & 25 & 0.0010 & 10 & 55.00 \\
6 & 25 & 0.0505 & 30 & 46.75 \\
7 & 65 & 0.0010 & 10 & 60.82 \\
8 & 45 & 0.0505 & 30 & 14.69 \\
9 & 45 & 0.0505 & 10 & 35.27 \\
10 & 65 & 0.1000 & 10 & 61.00 \\
11 & 25 & 0.0010 & 50 & 61.51 \\
12 & 45 & 0.0505 & 30 & 132.00 \\
13 & 45 & 0.0505 & 50 & 62.77 \\
14 & 0.0505 & 30 & 63.91 \\
15 & 45 & 0.1000 & 50 & 96.10 \\
16 & 65 & 0.0505 & 30 & 74.40 \\
17 & 45 & 0.0505 & 30 & 61.68 \\
18 & 45 & 0.1000 & 30 & \\
19 & 45 & 0.1000 & 50 & 30 \\
\hline
\end{tabular}

\subsection{Antibacterial Activity of AgNPs}

\subsubsection{Bacteria selection}

In this study, Escherichia coli (O157:H7) ATCC 25922, Listeria monocytogenes ATCC 7644, Staphylococcus aureus ATCC 25923, and Salmonella typhimurium ATCC 14028 bacteria species were selected for determining of antibacterial activities of AgNPs because they are common foodborne pathogens. They are used here as representative gram positive (Listeria monocytogenes, Staphylococcus aureus) and gram negative (Escherichia coli (O157:H7), Salmonella typhimurium) pathogens.

\subsubsection{Culture and Inoculum Preparation}

Escherichia coli (O157:H7), Listeria monocytogenes, Staphylococcus aureus and Salmonella typhimurium cultures were obtained from the Microbiology Laboratory of Food Engineering Department of Mersin University. The bacterial cultures were grown on TSA slants and kept at $4{ }^{\circ} \mathrm{C}$. 
Isolated colonies obtained from the TSA slants were inoculated into TSB medium. The broth culture was incubated at $37^{\circ} \mathrm{C}$ for $24 \mathrm{~h}$. The optical density of the culture was adjusted between 0.08 to 0.1 at $625 \mathrm{~nm}$ to obtain inoculum size of $1 \times 10^{7}$ colony-forming unit $(\mathrm{CFU}) / \mathrm{mL}$ [7].

\subsubsection{Antibacterial Activity Tests}

Antimicrobial susceptibility was tested by the agar disk diffusion method on Mueller Hinton Agar. Surface of agar plate was inoculated by spreading of the test microorganism over entire surface. Then, antimicrobial discs with the diameter of $6 \mathrm{~mm}$ were treated with AgNPs solution and the excess solution was removed from discs. The Petri dishes were incubated at $37^{\circ} \mathrm{C}$ for $24 \mathrm{~h}$. The test compound diffuses into the agar and inhibits the growth of the test microorganism. The diameters of inhibition growth zones were measured with a digital caliper.

\section{RESULTS AND DISCUSSION}

\subsection{Optimization of Experimental Conditions of Green Synthesis of AgNPs}

The effects of experimental conditions such as temperature, $\mathrm{AgNO}_{3}$ concentration, and aqueous leaf extract volume on green synthesis of AgNPs were investigated by using RSM according to CCD. The experimental results were evaluated and the empirical relationship between the independent variables and the effective hydrodynamic diameter $(\mathrm{nm})$ of $\mathrm{AgNPs}(\mathrm{Y})$ was given in Eq. 2:

$\mathrm{Y}=78.6-0.79 \mathrm{~A}+25 \mathrm{~B}-1.475 \mathrm{C}+0.0046 \mathrm{~A}^{2}+5434 \mathrm{~B}^{2}+0.0103 \mathrm{C}^{2}+7.32 \mathrm{AB}+0.01580 \mathrm{AC}$ $-6.35 \mathrm{BC}$

Positive sign in front of the terms indicates synergistic effect whilst a negative sign specifies antagonistic effect. Accordingly, among the linear terms, only B term positively affected the response while the response was negatively affected by $\mathrm{A}$ and $\mathrm{C}$. In order to investigate the interaction among the variables, 3D response surfaces were plotted on the basis of the model equation (Figure 1. a-c). According to Figure 1, only $\mathrm{AgNO}_{3}$ concentration (B) significantly affected the effective hydrodynamic diameter of AgNPs. As B increased, the effective hydrodynamic diameter increased resulting from the substantially agglomeration of the AgNPs at high $\mathrm{AgNO}_{3}$ concentrations. Similarly, Rao et al. [8] found that the effective hydrodynamic diameter of AgNPs had a slight tendency to become larger with an increase in $\mathrm{AgNO}_{3}$ concentration. Sood et al. [9] indicated that increasing the concentration of $\mathrm{AgNO}_{3}$ concentration from $2 \mathrm{mM}$ to $10 \mathrm{mM}$ caused an increase in the size of AgNPs. Various similar findings were reported in literature [10-14].

Temperature and aqueous leaf extract volume were not significant model parameters but it could be said that the effective hydrodynamic diameter slightly increased with increase in temperature while it decreased with increase in aqueous leaf extract volume. This could be explained as follows; the increase in the temperature raised the kinetic energy of the AgNPs, thereby resulting the collision frequency between the nanoparticles and this led to the increase in agglomeration [15]. The increase of the effective hydrodynamic diameter of AgNPs with the increasing temperature was in accordance with the previous studies [16-20]. For instance, Sun et al. [16] reported that the average particle sizes of AgNPs were 91, 129 , and $175 \mathrm{~nm}$ at 25,40 , and $55^{\circ} \mathrm{C}$, respectively. Khan et al. [17] found that the size of AgNPs synthesized using tea leaf extract increased from $91 \mathrm{~nm}$ to $175 \mathrm{~nm}$ with an increase in the reaction temperature from 25 to $55^{\circ} \mathrm{C}$. Cheng et al. [18] indicated that the size of AgNPs synthesized at $90{ }^{\circ} \mathrm{C}$ for $4 \mathrm{~h}$ were bigger than those synthesized at $75^{\circ} \mathrm{C}$ for $6 \mathrm{~h}$.

Moreover, at high volumes of aqueous leaf extract, the biomolecules in the leaf extract acted as reducing agents and caped the nanoparticles protecting them from aggregation [21]. The relationship between the size of AgNPs and the amount of leaf extract was in agreement with the earlier investigations conducted 
by et al [22], et al [23], et al [24], and Sood et al [9]. Among them, Pourmortazavi et al. [22] obtained that increasing the amount of plant from $1 \%$ to $5 \%(\mathrm{w} / \mathrm{w})$ caused a decrease in the size of AgNPs. Also, Erjaee et al. [23], Iravani et al. [24], and Sood et al. [9] reported that the decrease in particle size of AgNPs was observed due to an increase in the extract amount.

Consequently, the optimum effective hydrodynamic diameter $(\mathrm{nm})$ of AgNPs was predicted as 32.7370 $\mathrm{nm}$ at temperature (A) of $25^{\circ} \mathrm{C}, \mathrm{AgNO}_{3}$ concentration (B) of $0.001 \mathrm{M}$, and aqueous leaf extract volume (C) of $50 \mathrm{~mL}$ from the quadratic model.
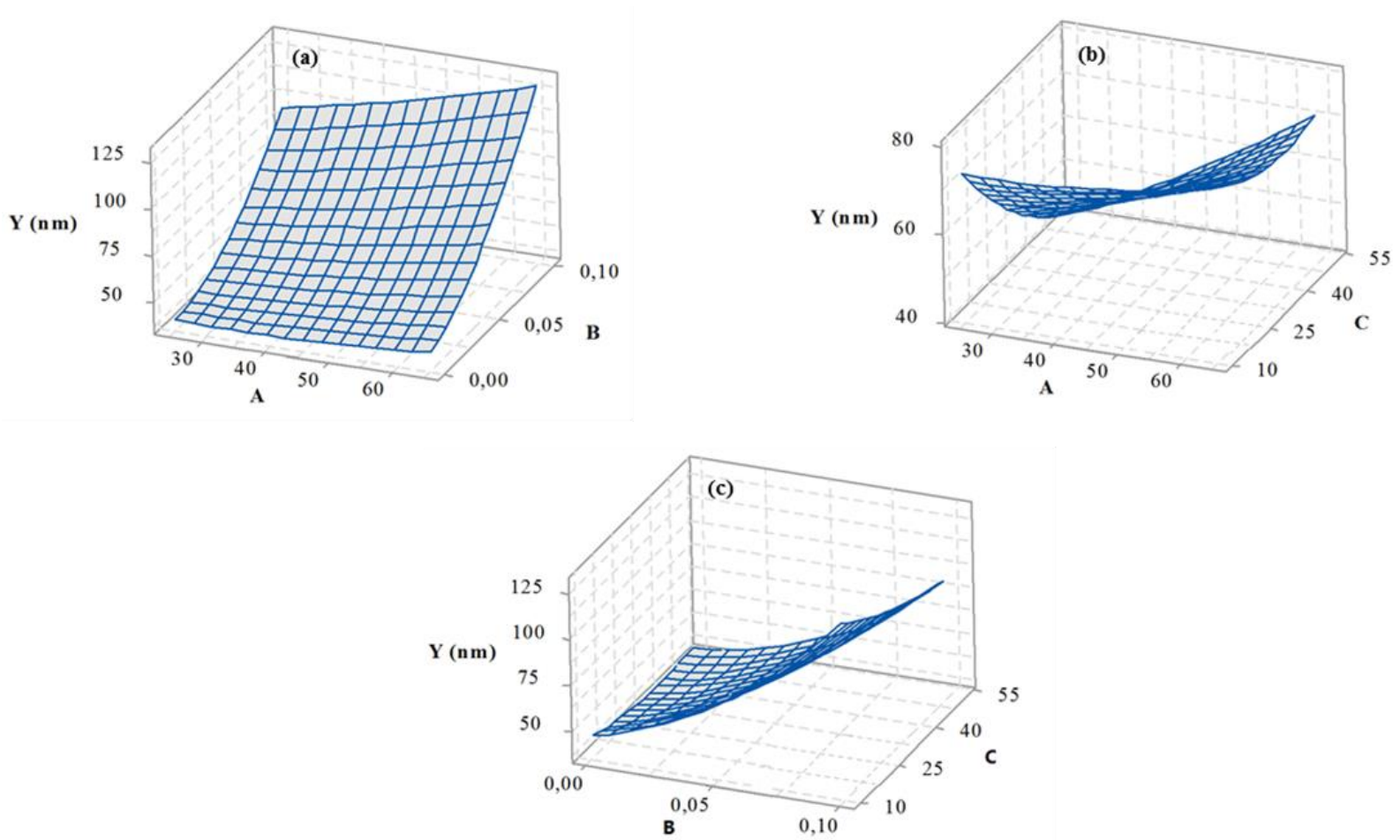

Figure 1. Response surface plots of the model showing the effective hydrodynamic diameter (nm) of AgNPs as a function (in coded levels) of: a. temperature and $\mathrm{AgNO}_{3}$ concentration, b. temperature and aqueous leaf extract volume, c. $\mathrm{AgNO}_{3}$ concentration and aqueous leaf extract volume

The statistical significance of the quadratic model equation was evaluated by F-test for analysis of variance (ANOVA) and the results of ANOVA were presented in Table 3. As can be seen from Table 3 , the model F-value of 31.36 and $\mathrm{P}$-value $<0.0001$ indicated that the model was statistically significant. Besides, the independent variable $\mathrm{B}, \mathrm{AgNO}_{3}$ concentration, was the only significant term (Pvalue $<0.0001$ ) for the quadratic model. The $R^{2}$ of 0.9658 was in conceivable agreement with the $R_{\text {adj }}^{2}$ of 0.9350. Adequate precision measures the signal (response) to noise (deviation) ratio, and a ratio greater than 4 is required. The ratio of 7.7034 implied an adequate signal and the quadratic model can be used to navigate the design space [6]. Consequently, this quadratic model could be used for the purpose of predicting future responses successfully for the green synthesis of AgNPs in the studied ranges.

The plot of the standardized residuals vs fitted value was presented in Figure 2. As can be seen from Figure 2, it exhibited nearly a funnel-shaped pattern because the variance of the response depended on the mean level of $\mathrm{Y}$, thus suggesting no need for transformation of the response variable [6].

Figure 3 showed that the points of data were close to a straight line $\left(\mathrm{R}^{2}=0.9658\right)$, which indicated a good correlation between the predicted and experimental responses. It could be concluded that the chosen quadratic model was acceptable for the experimental data of the green synthesis of AgNPs [25]. 
Arslantürk et al. / Eskişehir Tech. Univ. J. of Sci. and Technology A-Appl. Sci. and Eng. 20 (4) - 2019

Table 3. ANOVA results of the quadratic model

\begin{tabular}{|c|c|c|c|c|c|c|}
\hline Source & $\begin{array}{l}\text { Degree of } \\
\text { freedom }\end{array}$ & $\begin{array}{c}\text { Sum of } \\
\text { squares }\end{array}$ & $\begin{array}{c}\text { Mean } \\
\text { squares }\end{array}$ & F-value & P-value & Remarks \\
\hline Model & 9 & 16749.4 & 1861.0 & 31.36 & $<0.0001$ & Significant \\
\hline Linear & 3 & 14183.8 & 4727.9 & 79.67 & $<0.0001$ & Significant \\
\hline A & 1 & 870.3 & 870.3 & 14.67 & 0.003 & \\
\hline $\mathrm{B}$ & 1 & 12434.8 & 12434.8 & 209.54 & $<0.0001$ & Significant \\
\hline $\mathrm{C}$ & 1 & 878.7 & 878.7 & 14.81 & 0.003 & \\
\hline Square & 3 & 1510.2 & 503.4 & 8.48 & 0.004 & \\
\hline AA & 1 & 9.5 & 9.5 & 0.16 & 0.698 & \\
\hline $\mathrm{BB}$ & 1 & 487.5 & 487.5 & 8.22 & 0.017 & \\
\hline $\mathrm{CC}$ & 1 & 46.4 & 46.4 & 0.78 & 0.397 & \\
\hline 2-way interaction & 3 & 1055.4 & 351.8 & 5.93 & 0.014 & \\
\hline $\mathrm{AB}$ & 1 & 420.1 & 420.1 & 7.08 & 0.024 & \\
\hline $\mathrm{AC}$ & 1 & 319.4 & 319.4 & 5.38 & 0.043 & \\
\hline $\mathrm{BC}$ & 1 & 315.9 & 315.9 & 5.32 & 0.044 & \\
\hline Error & 10 & 593.4 & 59.3 & & & \\
\hline Lack of fit & 5 & 586.5 & 117.3 & 84.26 & $<0.0001$ & Significant \\
\hline Pure error & 5 & 7.0 & 1.4 & & & \\
\hline Total & 19 & 17342.8 & & & & \\
\hline
\end{tabular}

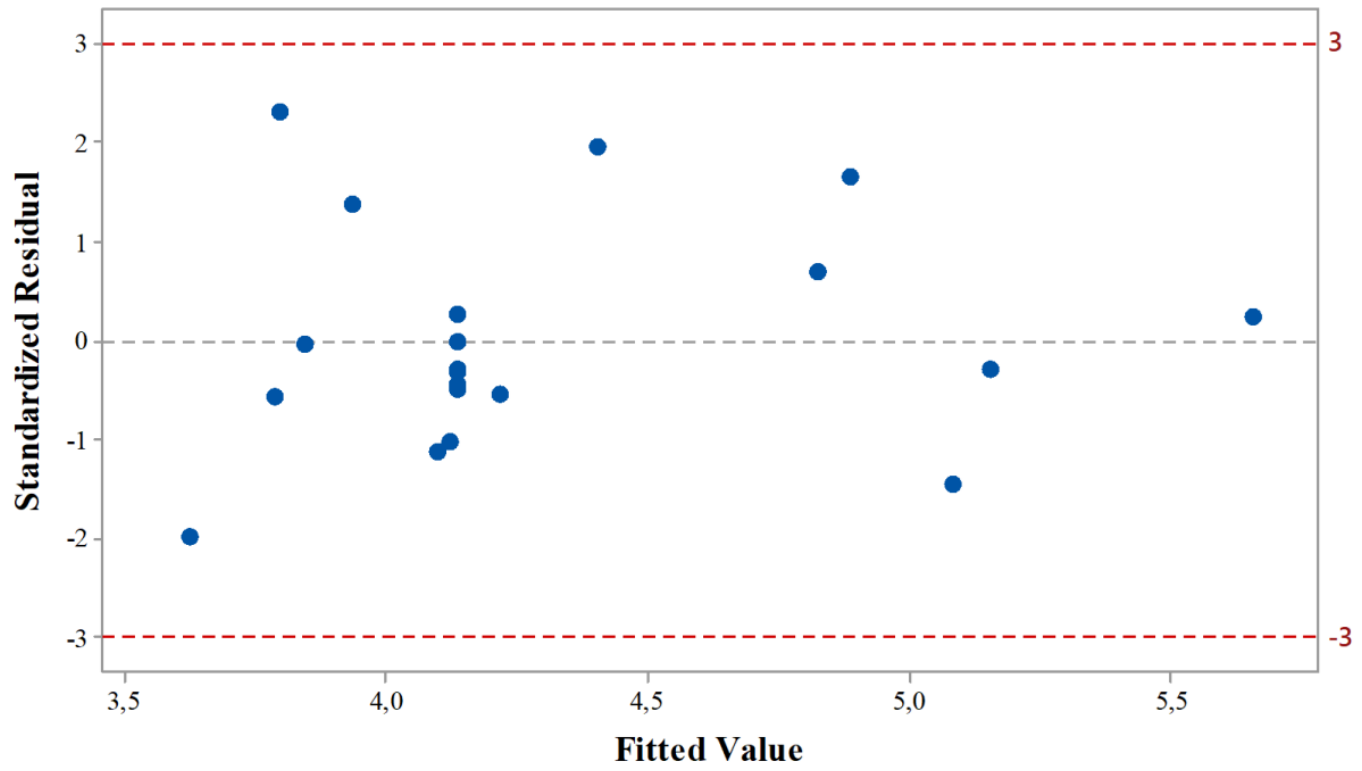

Figure 2. The plot of standardized residual vs fitted value 


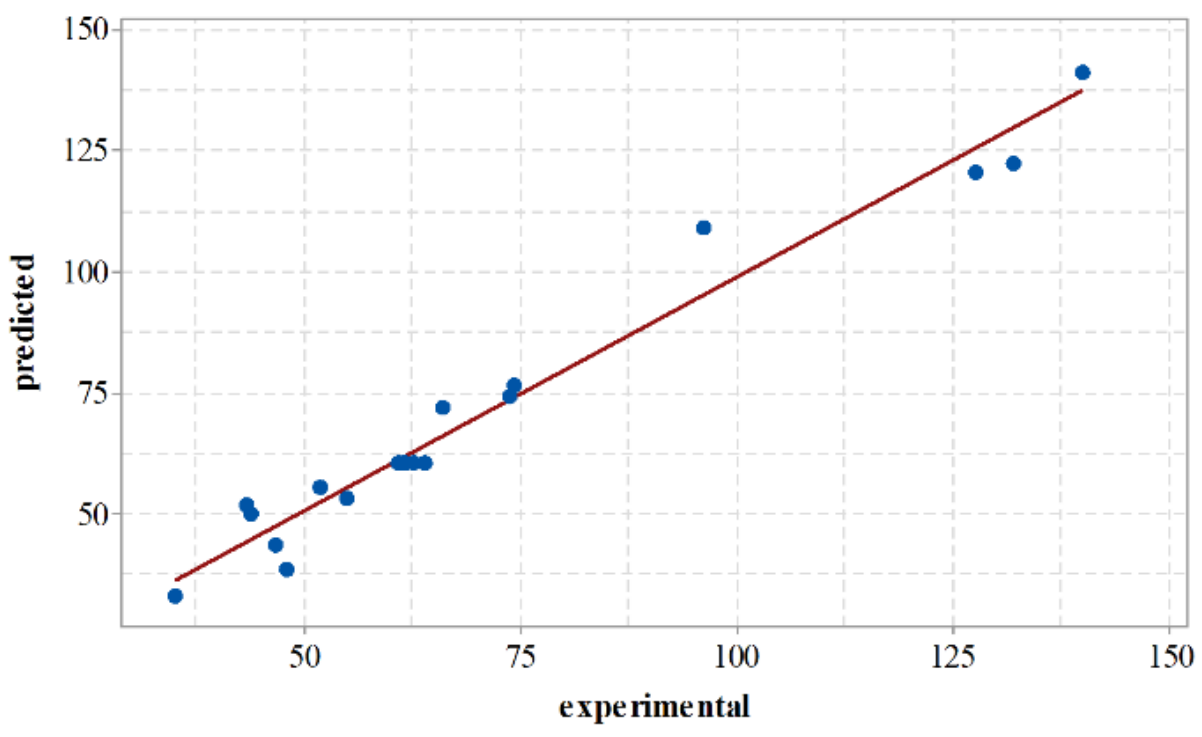

Figure 3. The experimental and predicted plot for the green synthesis of AgNPs

\subsection{Characterization of AgNPs}

The formation of AgNPs was firstly noted by visual observation of the color of $\mathrm{AgNO}_{3}$-aqeous leaf extract solution and then the UV-vis spectra of the solutions were performed against pure water with 1 mm optical path length quartz cuvette. Figure 4 presented that the color of the solution altered from light brown to dark brown by the time of synthesis progress indicating silver nanoparticle formation due to the surface plasmon resonance $\left(\lambda_{\mathrm{SPR}}, \mathrm{nm}\right)$ phenomenon. Also, as shown in Figure 4 , a characteristic and well-defined $\lambda_{\mathrm{SPR}}$ value for $\mathrm{AgNPs}$ was recorded at nearly $430 \mathrm{~nm}$ whereas $\mathrm{AgNO}_{3}$ solution (for control) did not exhibit any characteristic peak.

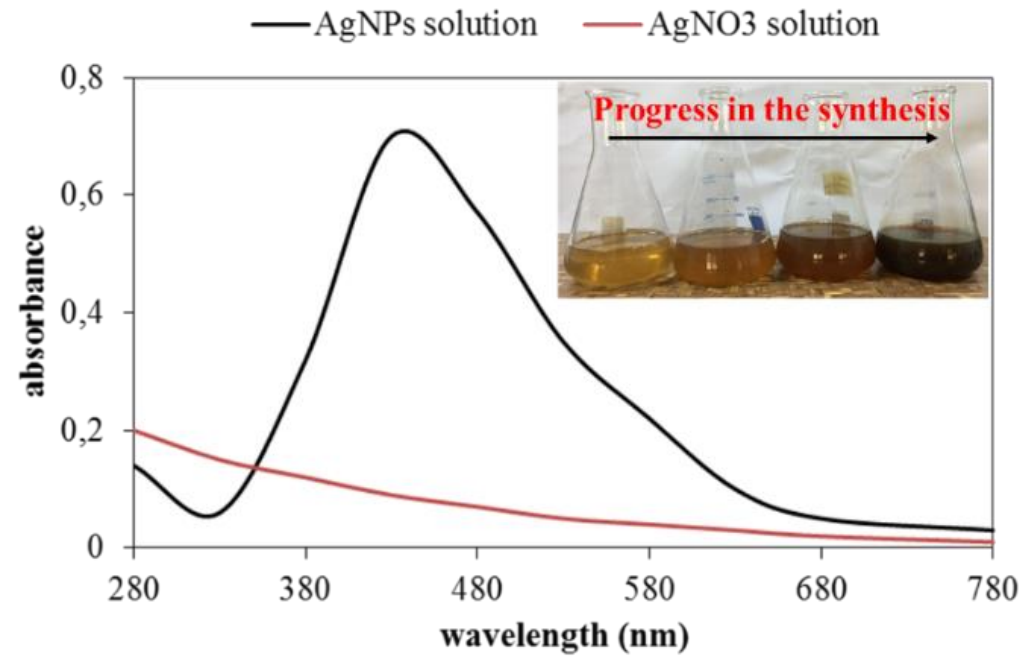

Figure 4. $\mathrm{UV}$-vis spectra of $\mathrm{AgNPs}$ and $\mathrm{AgNO}_{3}$ solutions along with the color change upon formation of silver nanoparticles

Besides, the values of $\lambda_{\mathrm{SPR}}$ were recorded for the run orders of $5\left(\mathrm{~A}=25^{\circ} \mathrm{C}, \mathrm{B}=0.001 \mathrm{M}\right.$, and $\left.\mathrm{C}=10 \mathrm{~mL}\right)$, $7\left(\mathrm{~A}=65^{\circ} \mathrm{C}, \mathrm{B}=0.001 \mathrm{M}\right.$, and $\left.\mathrm{C}=10 \mathrm{~mL}\right), 11\left(\mathrm{~A}=25^{\circ} \mathrm{C}, \mathrm{B}=0.001 \mathrm{M}\right.$, and $\left.\mathrm{C}=50 \mathrm{~mL}\right), 15\left(\mathrm{~A}=65^{\circ} \mathrm{C}, \mathrm{B}=0.1\right.$ $\mathrm{M}$, and $\mathrm{C}=50 \mathrm{~mL})$, and $19\left(\mathrm{~A}=25^{\circ} \mathrm{C}, \mathrm{B}=0.1 \mathrm{M}\right.$, and $\left.\mathrm{C}=50 \mathrm{~mL}\right)$ and it was presented in Figure 5. As seen

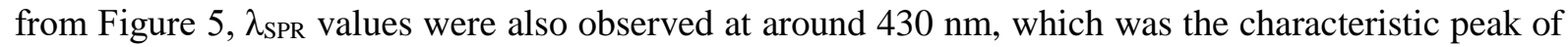
AgNPs. Mainly, the sharp and narrow peak shows the stable and smaller formation of nanoparticles in 
the homogeneous distribution [15]. Hence, it can be seen from Figure 5 that the maximum $\lambda_{\text {SPR }}$ value, indicating the formation of smallest nanoparticles, was detected for the run order of 11, the optimum synthesis conditions. Consequently, the decrease in $\lambda_{\mathrm{SPR}}$ with increase in temperature and $\mathrm{AgNO}_{3}$ concentration, and with decrease in aqueous leaf extract volume could be attributed to the decrease in the diameters of AgNPs. These observations confirmed the ANOVA results.

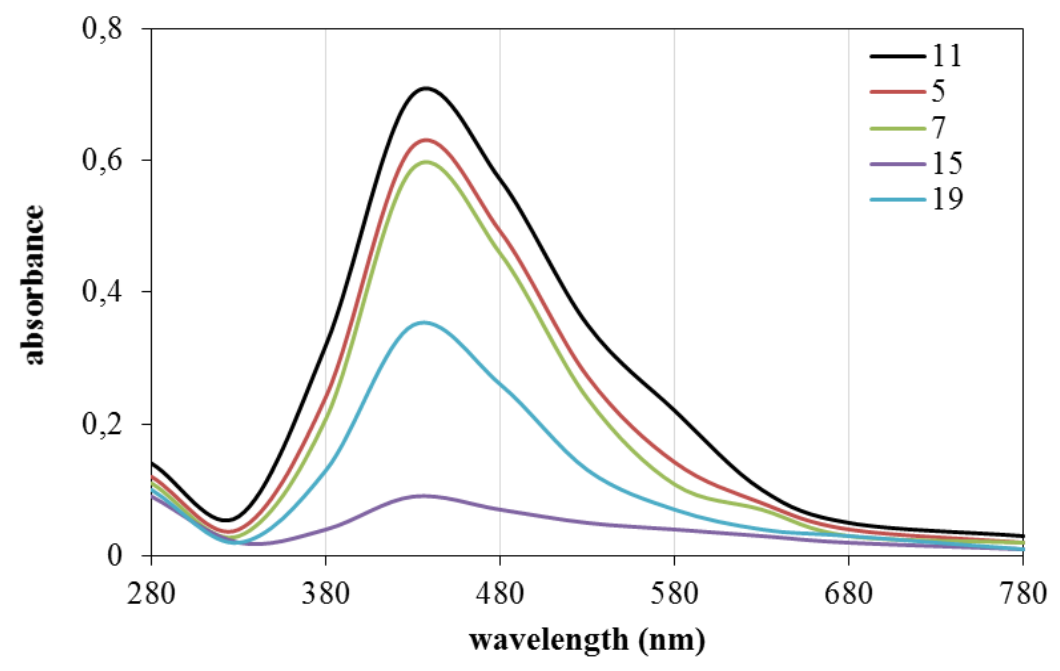

Figure 5. UV-vis spectra of AgNPs solution at different experimental conditions

In the green synthesis method, +1 valent silver ion in $\mathrm{AgNO}_{3}$ structure is reduced to zero valent silver, silver nanoparticles (AgNPs), with the aid of the various compounds in the aqueous leaf extract such as proteins, amino acids, organic acids, vitamins, flavonoids, alkaloids, polyphenols, terpenoids, and polysaccharides. In order to determine the functional groups of the synthesized AgNPs at the optimum experimental conditions, FT-IR analysis was performed and it was presented in Figure 6. O-H group in polyphenols or proteins/enzymes or polysaccharide $\left(3400 \mathrm{~cm}^{-1}\right),=\mathrm{C}-\mathrm{H}$ alkenes $\left(2980 \mathrm{~cm}^{-1}\right),-\mathrm{COOH}$ carbonyl group $\left(1630 \mathrm{~cm}^{-1}\right),-\mathrm{C}-\mathrm{H}$ alkane $\left(1387 \mathrm{~cm}^{-1}\right), \mathrm{C}-\mathrm{N}$ stretch aliphatic amines $\left(1091 \mathrm{~cm}^{-1}\right), \mathrm{C}-\mathrm{N}$ amines $\left(1005 \mathrm{~cm}^{-1}\right), \mathrm{C}-\mathrm{C}$ bending $\left(660 \mathrm{~cm}^{-1}\right)$ peaks were observed from FT-IR spectra of AgNPs. These FTIR peaks confirmed that the aforementioned compounds in the aqueous leaf extract played important roles in the reduction of $\mathrm{Ag}^{1+}\left(\mathrm{AgNO}_{3}\right)$ into $\mathrm{Ag}^{0}$ (AgNPs) [26, 27].

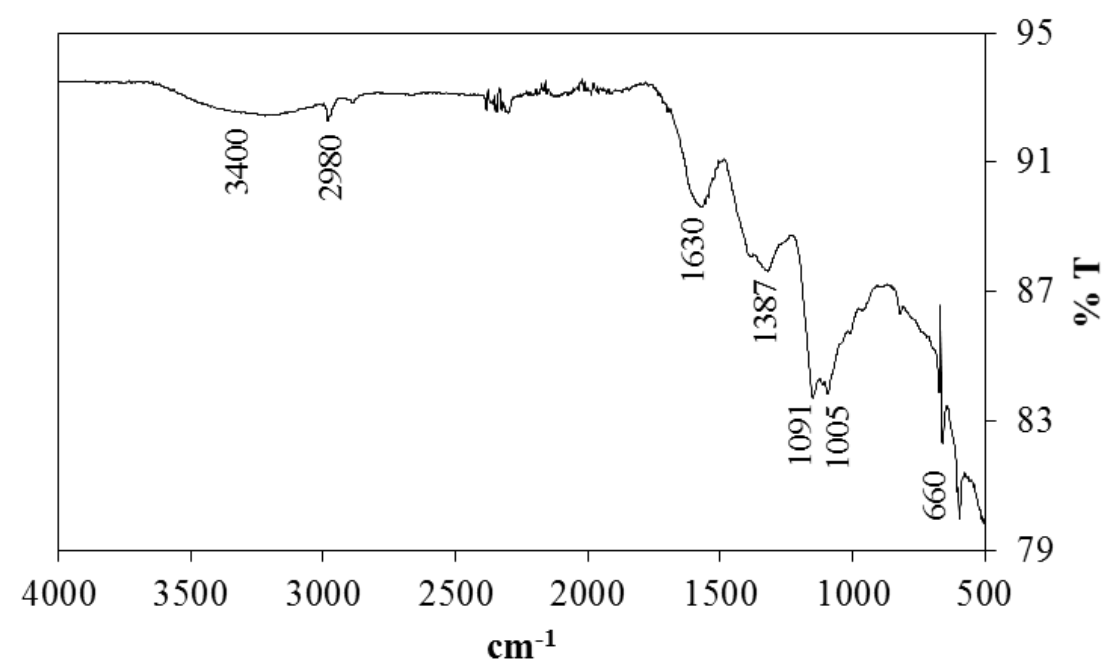

Figure 6. FT-IR spectra of AgNPs 
The distribution of effective hydrodynamic diameters of the synthesized AgNPs at the optimum experimental conditions was measured by DLS technique and the results were represented in Figure 7. DLS analysis showed that the mean diameter of AgNPs was determined as $35.27 \mathrm{~nm}$ with low polydispersity index (PDI) of 0.377 .

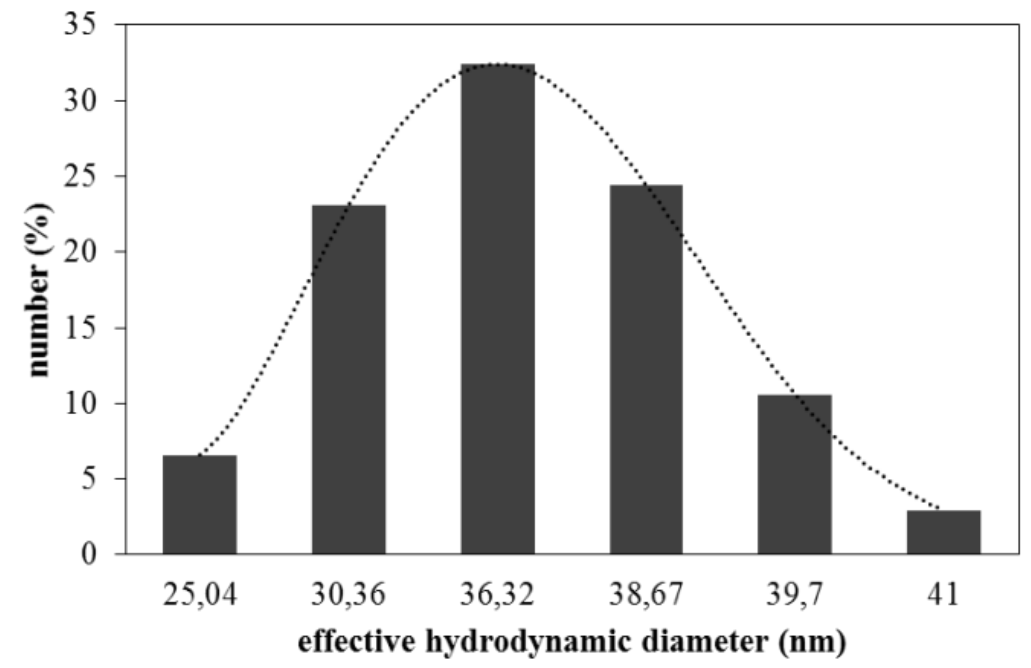

Figure 7. The distribution of effective hydrodynamic diameters of AgNPs

The morphology of the synthesized AgNPs at the optimum experimental conditions was evaluated by SEM analysis for the optimum synthesis conditions and the obtained SEM image was given in Figure 8. As seen from this Figure, nearly spherical-like nanoparticles were synthesized successfully and also, it could be said that the mean diameter of AgNPs in SEM image was smaller than that observed with DLS technique because in DLS technique, the hydrodynamic diameters of materials dispersed in solvents are measured, that resulting in the bigger structures.

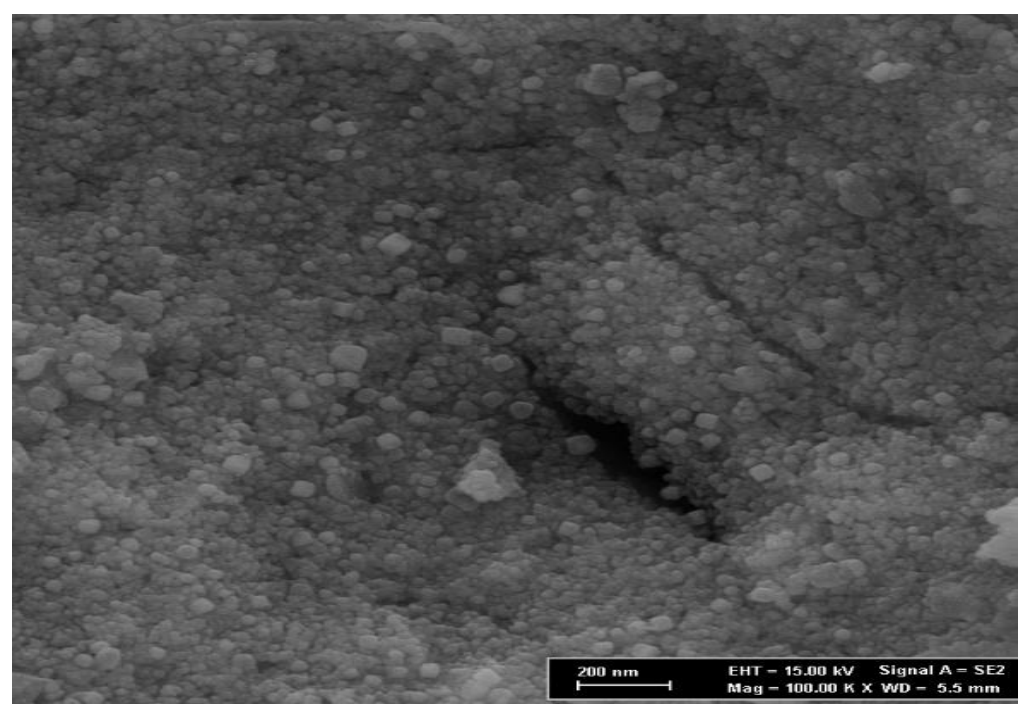

Figure 8. SEM image of AgNPs

In order to investigate the crystal phase of the synthesized AgNPs at the optimum experimental conditions, XRD analysis was performed in $2 \theta$ value ranging from $30^{\circ}$ to $90^{\circ}$ for the optimum synthesis conditions $\left(\mathrm{A}=25^{\circ} \mathrm{C}, \mathrm{B}=0.001 \mathrm{M}\right.$, and $\left.\mathrm{C}=50 \mathrm{~mL}\right)$. XRD pattern of AgNPs (Figure 9) exhibited peaks at $2 \theta$ angles of $38.10,44.28,64.41$, and $77.36^{\circ}$ which corresponded to the [1 111 ], [ [ 200 ], [ [2 20 ], and [3 1 1], crystal planes of a cubic lattice structure of AgNPs. The unassigned peaks stemmed from the 
crystallization of bio-organic phase (as obtained in FT-IR spectra) on the surface of the silver nanoparticles due to the aqueous leaf extract [21].

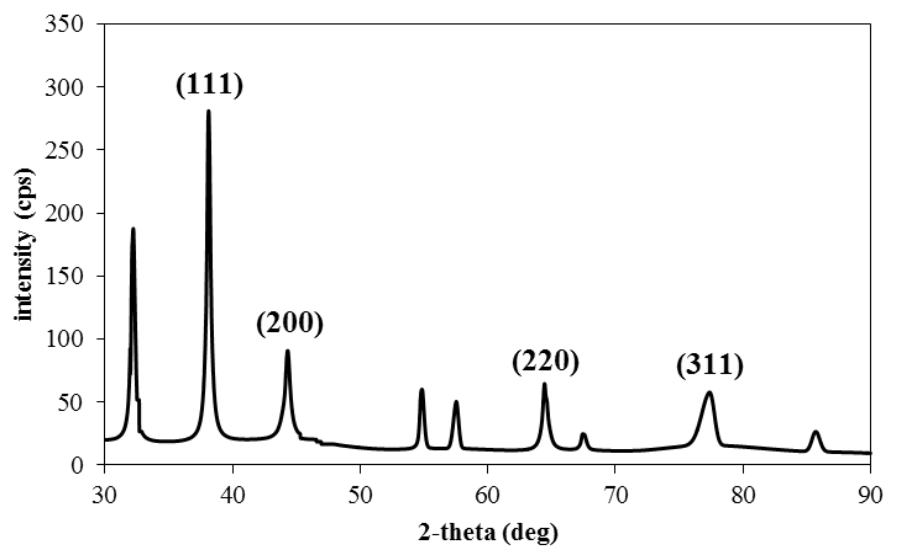

Figure 9. XRD pattern of AgNPs

\subsection{Antibacterial Activity of AgNPs}

The synthesized AgNPs at the optimum experimental conditions were effective against all selected bacteria, S. typhimurium, E. coli O157:H7, S. aureus, and L. monocytogenes, and the inhibition zone diameters of test compound for these bacteria were given in Table 4 and Figure 10. The results indicated that AgNPs had stronger inhibitory effected on growth of L. monocytogenes than the other bacteria.

Table 4. The inhibition zone diameters

\begin{tabular}{cc}
\hline Bacteria & Inhibition zone diameter $(\mathbf{m m})$ \\
\hline S. typhimurium & $10.00 \pm 0.87$ \\
E. coli $\mathrm{O} 157: \mathrm{H} 7$ & $10.55 \pm 0.68$ \\
S. aureus & $10.72 \pm 0.63$ \\
L. monocytogenes & $12.26 \pm 0.23$ \\
\hline
\end{tabular}
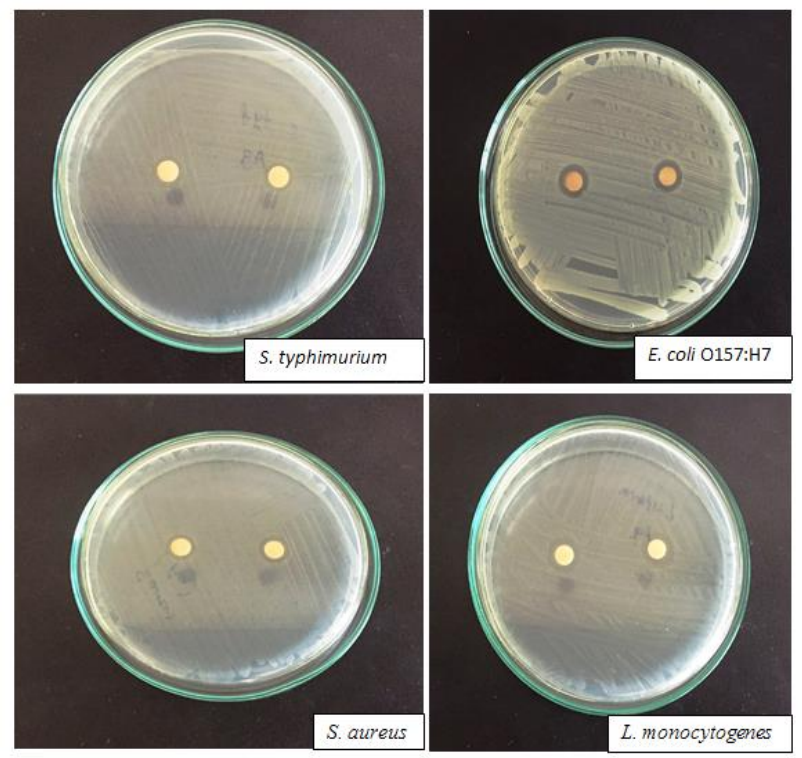

Figure 10. Antibacterial activity of AgNPs 
A literature survey has been done for antibacterial activities of AgNPs synthesized via various methods, and the literature summary was presented in Table 5. Accordingly, there are few studies investigating the antibacterial activity against these bacteria for AgNPs synthesized via green synthesis using leaf extract in the literature. Among them, AgNPs synthesized in this study had a competitive antibacterial activity. Moreover, it was observed in this study that the inhibition zone diameters against the studied bacteria were close to the results in the literature shown in Table 4. Consequently, these results suggested that AgNPs could be successfully used as effective antimicrobial agents in food packaging to control the growth of pathogenic bacteria.

Table 5. The inhibition zone diameters against the bacteria for various AgNPs based antibacterial agents in the literature

\begin{tabular}{|c|c|c|c|c|c|c|c|}
\hline \multirow[b]{2}{*}{ Agent } & \multirow[b]{2}{*}{$\begin{array}{l}\text { Synthesis } \\
\text { Method }\end{array}$} & \multirow[b]{2}{*}{$\begin{array}{c}\text { Reductant } \\
\text { agent }\end{array}$} & \multicolumn{4}{|c|}{ Inhibition zone diameter $(\mathrm{mm})$ against the bacteria } & \multirow[b]{2}{*}{ Reference } \\
\hline & & & $\begin{array}{c}S . \\
\text { typhimurium }\end{array}$ & $\begin{array}{c}\text { E. coli } \\
\text { O157:H7 }\end{array}$ & S. aureus & $\begin{array}{c}L . \\
\text { monocytogenes }\end{array}$ & \\
\hline AgNPs & Green synthesis & Leaf extract & $10.00 \pm 0.87$ & $10.55 \pm 0.68$ & $10.72 \pm 0.63$ & $12.26 \pm 0.23$ & This study \\
\hline AgNPs & Green synthesis & Leaf extract & - & - & 10 & 20 & {$[28]$} \\
\hline \multirow{2}{*}{ AgNPs/PVA } & \multirow{2}{*}{ Green synthesis } & Leaf extract & - & - & - & $13 \pm 1.5$ & \multirow{2}{*}{ [29] } \\
\hline & & Callus extract & - & - & - & $18 \pm 2.0$ & \\
\hline AgNPs & $\begin{array}{l}\text { Photo-mediated } \\
\text { green synthesis }\end{array}$ & Leaf extract & $10.22 \pm 0.25$ & $8.14 \pm 6.05$ & - & - & [30] \\
\hline AgNPs & Green synthesis & Bark extract & - & $13.00 \pm 1.76$ & $14.12 \pm 3.00$ & - & [31] \\
\hline $\mathrm{AgNPs}$ & Green synthesis & Fruit juice & $13.0 \pm 0.0$ & $12.5 \pm 0.1$ & $15.5 \pm 0.4$ & $13.3 \pm 0.3$ & [32] \\
\hline AgNPs & Green synthesis & Fungal filtrate & $12 \pm 0.29$ & - & $16 \pm 0.69$ & - & [33] \\
\hline AgNPs & Green synthesis & Bacteria strain & $11 \pm 0$ & $8 \pm 0$ & $11 \pm 0$ & $10 \pm 0$ & [34] \\
\hline $\begin{array}{c}\mathrm{Ag} / \mathrm{MMT} \\
\text { nanocomposites }\end{array}$ & $\begin{array}{l}\text { Chemical } \\
\text { Reduction }\end{array}$ & $\mathrm{NaBH}_{4}$ & - & $9.80 \pm 0.41$ & $9.95 \pm 0.10$ & - & [35] \\
\hline $\begin{array}{c}\mathrm{Na}-\mathrm{Alg} / \mathrm{Vc}- \\
\text { based AgNPs }\end{array}$ & $\begin{array}{l}\text { Chemical } \\
\text { Reduction }\end{array}$ & Ascorbic acid & $12.75 \pm 0.15$ & - & $12.58 \pm 0.22$ & - & [36] \\
\hline
\end{tabular}

\section{CONCLUSION}

In this work, an ecological method for synthesizing silver nanoparticles (AgNPs) was established by using avocado (Persea americana) leaf as a biological reductant and capping agent. The characterization studies of AgNPs were conducted by zetasizer (with DLS technique), FTIR, UV-vis spectrophotometer, XRD, and SEM. According to UV-vis spectra; AgNPs had characteristic surface plasmon resonance band at around $430 \mathrm{~nm}$ and it was a narrow and sharp band, which indicating the formation of homogeneous, stable, and small nanoparticles. FT-IR spectrum showed that AgNPs contained $\mathrm{O}-\mathrm{H}$, $=\mathrm{C}-\mathrm{H},-\mathrm{COOH},-\mathrm{C}-\mathrm{H}, \mathrm{C}-\mathrm{N}, \mathrm{C}-\mathrm{N}, \mathrm{C}-\mathrm{C}$ groups and the obtained results indicated that the various compounds in the aqueous leaf extract played important roles in the synthesis of AgNPs. The size distribution obtained by DLS showed that the synthesized AgNPs had a relatively narrow size distribution (25-41 nm) and the mean effective hydrodynamic diameter of AgNPs was obtained as $35.27 \mathrm{~nm}$. SEM analysis results indicated that the green-synthesized particles were in nearly sphericallike structure and nano-size. XRD pattern exhibited the characteristic peaks of cubic lattice structure of AgNPs. Moreover, response surface methodology (RSM) was practicable to optimize the effective hydrodynamic diameter (nm) of AgNPs for the green synthesis method. According to RSM, $\mathrm{AgNO}_{3}$ concentration significantly influenced the size of AgNPs. Besides, it was observed from response surface plots that the effective hydrodynamic diameter slightly decreased with decrease in temperature while it decreased with increase in aqueous leaf extract volume. The smallest particle size was obtained at the optimum synthesis conditions of temperature $25^{\circ} \mathrm{C}, \mathrm{AgNO}_{3}$ concentration $0.001 \mathrm{M}$, and aqueous leaf extract volume $50 \mathrm{~mL}$. Besides, the antibacterial activity of AgNPs was investigated and it was found that AgNPs synthesized at the optimum conditions were effective against $S$. typhimurium, E. coli O157:H7, S. aureus, and L. monocytogenes. Consequently, the present work has revealed significant outputs to synthesis of an effective antibacterial agent, which could be important for the contribution to the related literature. 


\section{REFERENCES}

[1] Mehmood A, Murtaza G, Bhatti TM, Raffi M, Kausar R. Antibacterial efficacy of silver nanoparticles synthesized by a green method using bark extract of Melia azedarach L. J Pharm Innov 2014; 9(3): 238-245.

[2] Umer A, Naveed S, Ramzan N, and Rafique MS. Selection of a suitable method for the synthesis of copper nanoparticles. Nano 2012; 7(05): 1230005.

[3] Ahmad A, Wei Y, Syed F, Tahir K, Rehman AU, Khan A, Yuan Q. The effects of bacteriananoparticles interface on the antibacterial activity of green synthesized silver nanoparticles. Microb Pathog 2017; 102: 133-142.

[4] Sun L, Wan S, Yu Z, and Wang L. Optimization and modeling of preparation conditions of $\mathrm{TiO}_{2}$ nanoparticles coated on hollow glass microspheres using response surface methodology. Sep Purif Technol 2014; 125: 156-162.

[5] Awwad AM, Salem NM, Abdeen AO, Green synthesis of silver nanoparticles using carob leaf extract and its antibacterial activity. IJIC 2013; 4(1): 1-6.

[6] Özer A, Gürbüz G, Çalimli A, Körbahti BK. Biosorption of copper (II) ions on Enteromorpha prolifera: application of response surface methodology (RSM). Chem Eng J 2009; 146(3): 377387.

[7] Gherardi R, Becerril R, Nerin C, Bosetti O. Development of a multilayer antimicrobial packaging material for tomato puree using an innovative technology. LWT-Food Science and Technology 2016; 72: 361-367.

[8] Rao B, Tang RC. Green synthesis of silver nanoparticles with antibacterial activities using aqueous Eriobotrya japonica leaf extract. Adv Nat Sci-Nanosci 2017; 8(1): 015014.

[9] Sood R, Chopra DS. Optimization of reaction conditions to fabricate Ocimum sanctum synthesized silver nanoparticles and its application to nano-gel systems for burn wounds. Mater. Sci. Eng. C 2018; 92: 575-589.

[10] Yıldız N, Ateş Ç, Yılmaz M, Demir D, Yıldız A, Çalımlı A. Investigation of lichen based green synthesis of silver nanoparticles with response surface methodology. Green Process Synth 2014; 3(4): 259-270.

[11] Manosalva N, Tortella G, Diez MC, Schalchli H, Seabra AB, Durán N, Rubilar O. Green synthesis of silver nanoparticles: effect of synthesis reaction parameters on antimicrobial activity. World $\mathbf{J}$ Microb Biot 2019; 35(6): 88.

[12] Htwe YZN, Chow WS, Suda Y, Mariatti M. Effect of Silver Nitrate Concentration on the Production of Silver Nanoparticles by Green Method. Mater Today: Proceedings 2019; 17: 568573.

[13] Dong C, Zhang X, Cai H, Cao C. Green synthesis of biocompatible silver nanoparticles mediated by Osmanthus fragrans extract in aqueous solution. Optik 2016; 127(22): 10378-10388.

[14] Khodaie M, Ghasemi N, Ramezani M. Green synthesis of silver nanoparticles using (Eryngium Campestre) leaf extract. Iran. Chem. Commun 2019; 7: 502-511. 
[15] Gade A, Gaikwad S, Duran N, and Rai M. Green synthesis of silver nanoparticles by Phoma glomerata. Micron 2014; 59: 52-59.

[16] Sun Q, Cai X, Li J, Zheng M, Chen Z, Yu CP. Green synthesis of silver nanoparticles using tea leaf extract and evaluation of their stability and antibacterial activity. Colloid Surf A Physicochem Eng Asp 2014; 444: 226-231.

[17] Khan M, Shaik MR, Adil SF, Khan ST, Al-Warthan A, Siddiqui MRH, Tremel W. Plant extracts as green reductants for the synthesis of silver nanoparticles: lessons from chemical synthesis. Dalton Trans 2018; 47(35): 11988-12010.

[18] Cheng F, Betts JW, Kelly SM, Schaller J, Heinze T. Synthesis and antibacterial effects of aqueous colloidal solutions of silver nanoparticles using aminocellulose as a combined reducing and capping reagent. Green Chem 2013; 15(4): 989-998.

[19] Ping Y, Zhang J, Xing T, Chen G, Tao R, Choo, KH. Green synthesis of silver nanoparticles using grape seed extract and their application for reductive catalysis of Direct Orange 26. J Ind Eng Chem 2018; 58: 74-79.

[20] Jiang XC, Chen WM, Chen CY, Xiong SX, Yu AB. Role of temperature in the growth of silver nanoparticles through a synergetic reduction approach. Nanoscale Res Lett 2011; 6(1): 32.

[21] Khalil MM, Ismail EH, El-Baghdady KZ, and Mohamed D. Green synthesis of silver nanoparticles using olive leaf extract and its antibacterial activity. Arab J Chem 2014; 7(6): 1131-1139.

[22] Pourmortazavi SM, Taghdiri M, Makari V, Rahimi-Nasrabadi M. Procedure optimization for green synthesis of silver nanoparticles by aqueous extract of Eucalyptus oleosa. Spectrochim Acta A 2015; 136: 1249-1254.

[23] Erjaee H, Rajaian H, Nazifi S. Synthesis and characterization of novel silver nanoparticles using Chamaemelum nobile extract for antibacterial application. Adv Nat Sci-Nanosci 2017; 8(2): 025004 .

[24] Iravani S, Zolfaghari B. Green synthesis of silver nanoparticles using Pinus eldarica bark extract. Biomed Res Int 2013; 2013: 1-5.

[25] Fakhri A. Investigation of mercury (II) adsorption from aqueous solution onto copper oxide nanoparticles: optimization using response surface methodology. Process Saf Environ 2015; 93: 18 .

[26] Kathiraven T, Sundaramanickam A, Shanmugam N, and Balasubramanian T. Green synthesis of silver nanoparticles using marine algae Caulerpa racemosa and their antibacterial activity against some human pathogens. Appl Nanosci 2015; 5(4): 499-504.

[27] Muthukumaran U, Govindarajan M, Rajeswary M, Hoti SL. Synthesis and characterization of silver nanoparticles using Gmelina asiatica leaf extract against filariasis, dengue, and malaria vector mosquitoes. Parasitol Res 2015; 114(5): 1817-1827.

[28] Awwad AM, Salem NM, Abdeen AO. Biosynthesis of silver nanoparticles using Olea europaea leaves extract and its antibacterial activity. Nanosci Nanotechnol 2012; 2(6): 164-170. 
[29] Nabikhan A, Kandasamy K, Raj A, Alikunhi NM. Synthesis of antimicrobial silver nanoparticles by callus and leaf extracts from saltmarsh plant, Sesuvium portulacastrum L. Colloid Surface B 2010; 79(2): 488-493.

[30] Patra JK, Das G, Kumar A, Ansari A, Kim H, Shin HS. Photo-mediated Biosynthesis of Silver Nanoparticles Using the Non-edible Accrescent Fruiting Calyx of Physalis peruviana L. Fruits and Investigation of its Radical Scavenging Potential and Cytotoxicity Activities. J Photochem Photobiol B 2018; 188: 116-125.

[31] Ontong JC, Paosen S, Shankar S, Voravuthikunchai SP. Eco-friendly synthesis of silver nanoparticles using Senna alata bark extract and its antimicrobial mechanism through enhancement of bacterial membrane degradation. J Microbiol Methods 2019; 105692.

[32] Puišo J, Jonkuvienė D, Mačionienė I, Šalomskienė J, Jasutienė I, Kondrotas R. Biosynthesis of silver nanoparticles using lingonberry and cranberry juices and their antimicrobial activity. Colloid Surface B 2014; 121: 214-221.

[33] Dar MA, Ingle A, Rai M. Enhanced antimicrobial activity of silver nanoparticles synthesized by Cryphonectria sp. evaluated singly and in combination with antibiotics. Nanomedicine: NBM 2013; 9(1): 105-110.

[34] Yurtluk T, Akçay FA, Avcı A. Biosynthesis of silver nanoparticles using novel Bacillus sp. SBT8. Prep Biochem Biotech 2018; 48(2): 151-159.

[35] Shameli K, Ahmad MB, Zargar M, Yunus WMZW, Rustaiyan A, Ibrahim NA. Synthesis of silver nanoparticles in montmorillonite and their antibacterial behavior. Int J Nanomedicine 2011; 6: 581.

[36] Shao Y, Wu C, Wu T, Yuan C, Chen S, Ding T, Hu Y. Green synthesis of sodium alginate-silver nanoparticles and their antibacterial activity. Int J Biol Macromol 2018; 111: 1281-1292. 